\title{
Princípios da Organização e do Emprego de Forças Especiais em Escala Mundial
}

\author{
Principles of Organization and Use of Special Forces on a World Scale
}

\author{
Principios de la Organización y del Empleo de Fuerzas Especiales en Escala \\ Mundial
}

\author{
Antenor Alves Silva ${ }^{1}$ \\ Vinício Carrilho Martinez ${ }^{2}$
}

\begin{abstract}
RESUMO: Muitos Estados soberanos, além da Organização do Tratado do Atlântico Norte (OTAN) e da União Europeia (UE), contam com o serviço de tropas militares especializadas para realização de operações que demandam maiores velocidade, precisão e sigilo, seja no seu próprio território ou além de suas fronteiras, caso sejam do seu interesse político ou econômico, pois nem sempre a diplomacia consegue atingir os objetivos institucionais de modo eficaz. Essas ações militares são executadas pelos mais diversos tipos de forças especiais - cujos modi operandi dependerão, basicamente, das doutrinas de emprego operacional que as orientam - e visam, entre outros interesses, neutralizar uma grande lista de ameaças, que vai desde movimentos insurgentes domésticos, como no fim da União Soviética, até grupos terroristas transnacionais, como visto desde a criação do Estado de Israel em 1948. Com características táticas, estratégicas, humanas e materiais distintas das operações militares convencionais, as operações especiais conduzidas pelas Forças Armadas passam a figurar entre um dos problemas mais sensíveis das relações internacionais contemporâneas. Compreender implicações políticas e espaciais desse tema cresce em importância haja vista ser factível verificar outras manifestações geopolíticas, como a fragmentação do princípio clássico de soberania; e sua ligação com outro fenômeno político, a guerra.
\end{abstract}

PALAVRAS-CHAVE: Forças armadas. Operações especiais. Relações internacionais. Soberania. Território.

ABSTRACT: Many sovereign States, in addition to the North Atlantic Treaty Organization (NATO) and the European Union (EU), count with the service of FORCE Sized military troops to carry out operations that demand greater speed, accuracy and secrecy, either in their own territory or beyond their boundaries, if they are in their political or economic interest, because diplomacy is not always able to achieve the institutional objectives effectively. These military actions are executed by the most diverse types of special forces - whose modi operandi will depend basically on the doctrines of operational employment that guide them - and aim, among other interests, to neutralize a great list of threats, ranging from domestic insurgent movements, such as in the end of Soviet Union, to

\footnotetext{
${ }^{1}$ Mestre em Geografia pela Fundação Universidade Federal de Rondônia. Leciona Geografia no Instituto Federal de Educação, Ciência e Tecnologia de Rondônia. antenor@email.com.

${ }^{2}$ Professor Associado do Departamento de Educação da Universidade Federal de São Carlos. Pós-Doutor em Ciência Política e em Educação - UNESP/Marília. prof.vinicio@ig.com.br.
} 
transnational terrorist groups, as seen since the creation of the State of Israel in 1948. With tactical, strategic, human, and material characteristics distinct from conventional military operations, the special operations conducted by the Armed Forces start to figure as one of the most sensitive problems in contemporary international relations. Understanding political and spatial implications of this theme grows in importance since it is feasible to verify other geopolitical manifestations, as the fragmentation of classical principle of sovereignty; and its link with another political phenomenon, the war.

KEYWORDS: Armed forces. Special operations. International relations. Sovereignty. Territory.

RESUMEN: Muchos Estados soberanos, además de la Organización del Tratado del Atlántico Norte (OTAN) y de la Unión Europea (UE), cuentan con el servicio de tropas militares especializadas para realizar operaciones que demandan mayor velocidad, precisión y secreto, ya sea en su propio territorio o además de sus fronteras, si son de su interés político o económico, pues no siempre la diplomacia logra alcanzar los objetivos institucionales de modo eficaz. Esas acciones militares son ejecutadas por los más diversos tipos de fuerzas especiales - cuyos modi operandi dependerán, básicamente, de las doctrinas de empleo operacional que las orientan - y pretenden, entre otros intereses, neutralizar una gran lista de amenazas, que van desde movimientos insurgentes domésticos, como en el fin de la Unión Soviética, hasta grupos terroristas transnacionales, como se ve desde la creación del Estado de Israel en 1948. Con características tácticas, estratégicas, humanas y materiales distintas de las operaciones militares convencionales, las operaciones especiales conducidas por las Fuerzas Armadas pasan a figurar entre uno de los problemas más sensibles de las relaciones internacionales contemporáneas. Comprender las implicaciones políticas y espaciales de este tema crece en importancia, ya que es factible verificar otras manifestaciones geopolíticas, como la fragmentación del principio clásico de soberanía; y su conexión con otro fenómeno político, la guerra.

PALABRAS-CLAVE: Fuerzas armadas. Operaciones especiales. Relaciones internacionales. Soberanía. Territorio.

\section{INTRODUÇÃO}

Partindo da hipótese de que eventualmente haverá cenários políticos nos quais a diplomacia não alcançaria os efeitos desejados por, pelo menos, uma das partes envolvidas - como a garantia da incolumidade de nacionais, de autoridades governamentais legalmente constituídas ou de ainda de instalações estratégicas, por exemplo, em áreas de risco iminente, que apresentem potencial instabilidade ou alto grau de entropia política - e nos quais uma campanha militar de grande envergadura seria inviável, far-se-ia necessária a intervenção de operadores especiais, ou seja, de forças militares que possuam características diferenciadas para realizar a ação demandada de modo preciso e em curto prazo.

Com vistas à resolução de conflitos de interesses dessa natureza, poderiam ser utilizados expedientes militares que não atenderiam necessariamente a convenções ou acordos que partem da premissa do respeito à soberania do polo passivo, ou seja, o 
emprego de ação militar altamente especializada e furtiva em solo estrangeiro - as operações especiais.

A problemática proposta por este artigo constitui-se, portanto, no reconhecimento da existência de unidades operacionais militares diferenciadas, que possuem características materiais, humanas, táticas e estratégicas nitidamente distintas das unidades convencionais. O que aparenta ser um problema pouco evidente, especialmente para os menos familiarizados com o jargão estratégico-militar, poderá ser mais bem compreendido no decorrer da exposição de elementos teóricos mais aprofundados.

Em linhas gerais, objetiva-se permitir a pesquisadores e analistas políticos, especialmente àqueles que se debruçam sobre temas geopolíticos de matriz militar, diferenciar as atividades operacionais executadas por tropas especiais a partir do conhecimento das suas doutrinas e respectivos modi operandi. Em viés mais específico, pretende-se apresentar aspectos das estruturas organizacionais das forças especiais e algumas implicações na organização do território em escala mundial.

\section{GUERRA, SOBERANIA E RELAÇÕES INTERNACIONAIS}

Antes de adentrar nas especificidades do tema proposto, é importante tratar de dois conceitos bastante caros ao estudo das relações internacionais: a guerra (DUROSELLE, 2000; WALTZ, 2004) e a soberania (AGNEW, 2009; AGNEW; CORBRIDGE, 1995). É possível compreender o primeiro como uma ação política, que nem sempre é tão simples determinar quando está sendo efetivamente empregada; e o segundo como um fim político, que nem sempre é possível afirmar se foi plenamente exercido, considerando sua acepção original, a despeito da afirmação de Duroselle (2000, p. 315,) que entende que a guerra "[...] aparece facilmente identificável, pois tem por característica a morte de inúmeros inocentes. [...]" [grifo nosso], pois a questão não é quantitativa, mas qualitativa sobre determinada porção do espaço geográfico.

Ao tratar-se de guerra, uma das leituras clássicas à qual se deve fazer referência é $D a$ guerra, de Clausewitz, que apresenta uma definição objetiva de guerra como:

[...] um ato de violência destinado a forçar o adversário a submeter-se à nossa vontade. [...] A violência [...] constitui, portanto, o meio; o fim será impor a nossa vontade ao inimigo. Para se atingir com total segurança este fim, tem de se desarmar o inimigo, sendo este desarmamento, por definição, o objetivo propriamente dito das operações de guerra. [...] Vemos, pois, que a guerra não é somente um ato político, mas um verdadeiro instrumento político, uma continuação das relações políticas, uma realização destas por outros meios (CLAUSEWITZ, 2010, p. 7- 8, 27, grifo nosso), 
Observe-se que, se reconfiguradas as proporções do fenômeno, o termo "violência" pode ser compreendido por "guerra" - independentemente dos meios utilizados - e a expressão "a nossa vontade" por "soberania". Acerca deste último, Morgenthau chama a atenção para seu significado quando afirma que:

[...] existe muita confusão acerca do [seu] significado [...] O conceito moderno de soberania [...] se referia, em termos jurídicos ao feito político fundamental dessa época: o surgimento de um poder centralizado que exercia sua autoridade legislativa e executiva dentro de um determinado território. [...] Este poder [...] era supremo (MORGENTHAU, 1986, p. 361, tradução nossa).

Não se tratam, portanto, de conceitos meramente nominativos, mas termos que representam fenômenos políticos complexos que estão em constante aperfeiçoamento. Nem guerra nem soberania têm o mesmo sentido quando consideradas as mais diversas escalas geográficas e recortes temporais haja vista sua natureza - como já dito - política.

Note-se que Carl von Clausewitz (1986) entende a beligerância como um recurso da política, que visa incessantemente submeter o inimigo aos desígnios da parte que deseja o confronto. Sob essa lógica, portanto, a ultima ratio de Estado não seria somente justificável em um contexto entrópico, mas, principalmente, desejável, pois seria uma forma de atuar positivamente no campo político - e com considerável chance de êxito, se bem calculada e executada.

Em outros termos, guerrear significaria atingir objetivos políticos por meio de ações mais ou menos violentas em vez de utilizar ferramentas diplomáticas, tais como os tratados internacionais e os acordos bilaterais. Vale observar ainda que Clausewitz (1986), não faz menção à escala de análise, mas trata o oponente somente como inimigo. Dada essa maleabilidade semântica, essa lógica pode ser facilmente transposta de uma escala individual para uma local ou de uma regional para a mundial.

Em última análise, o ato de guerra caracterizar-se-ia, portanto, como uma ação que visaria certa estabilidade, o que, de acordo com Gottmann (1982), um dos principais geógrafos do final do século $X X$, é um problema que já perpassava as preocupações relacionadas ao significado e às funções do território tanto em Platão quanto em Aristóteles. Ao vislumbrar outros campos, Gottmann (1982, p. 343, tradução nossa) aponta, entre outros, o "[...] interesse primário dos geógrafos políticos [...]" no "[...] equilíbrio de poder entre nações em tempo de paz ou de guerra".

Trata-se também de tema que é pauta obrigatória no planejamento dos organismos estratégicos e de defesa dos Estados e demais organizações de caráter internacional, pois um conflito armado nessa escala seria demasiadamente oneroso para as partes envolvidas - note-se que a ideia de equilíbrio está geralmente vinculada ao uso da força e de exércitos 
(MORGENTHAU, 1986). Trata-se, portanto, de uma problemática indubitavelmente geopolítica.

Em caráter explicativo, Correia (2010, p. 239) atenta para a diferenciação entre os termos geopolítica e geoestratégia: "[...] a geopolítica é a análise dos factores geográficos tendo como objectivo a política e a geoestratégia é a análise dos factores geográficos tendo como objectivo a estratégia [...]". Em seguida, adverte que "[...] quando política e estratégia se confundem também se confundirão a geopolítica e a geoestratégia". Mesmo que o sentido empregado no texto não faça referência à Geopolitik alemã, entende-se que conflitos conceituais como esse não impedem que os Estados lancem mão dos seus princípios para atingir seus objetivos políticos nos dias de hoje.

Dodds (2014, p. 1) complementa advertindo que "Geopolítica é um termo escorregadio. Embora possa ser pensado como um termo que se refere às várias geografias das relações internacionais tem sido frequentemente utilizado para representar uma abordagem demasiada pragmática pelo mundo. [...]".

Hedley Bull (2002, p. 117, grifo nosso), no entanto, sugere a expansão do entendimento do conceito de equilíbrio de poder quando afirma que "[...] normalmente quando usamos essa expressão queremos referir-nos ao poder militar, mas ela pode aludir a outras configurações de poder na política mundial. [...]". Certamente, a premissa de Bull é pertinente, além de ratificar o pressuposto de Clausewitz (2010), no qual a guerra é uma extensão das ações políticas. Na sequência, sobre a preservação do equilíbrio do poder, Bull chama atenção para suas funções históricas no sistema estatal moderno:

i) A existência de um equilíbrio de poder geral abrangendo a totalidade do sistema internacional serviu para impedir que o sistema fosse transformado, pela conquista, em um império universal. ii) Em determinadas regiões, a existência de equilíbrio de poder localizado serviu para proteger a independência dos estados, impedindo que fossem absorvidos ou dominados por uma potência localmente preponderante. iii) Quando houve equilíbrio de poder geral ou local surgiram as condições para o funcionamento de outras instituições das quais dependem a ordem internacional (diplomacia, guerra, direito internacional, administração pelas grandes potências). [...] É verdade que as tentativas de criar um equilíbrio de poder nem sempre resultaram na preservação da paz. No entanto, a principal função do equilíbrio de poder não é preservar a paz, mas sim preservar o próprio sistema de estados (BULL, 2002, p. 125, grifo nosso).

Nesse excerto, o grifo busca evidenciar a lógica mesma das relações internacionais contemporâneas em escala mundial: a manutenção do status quo tanto o quanto for possível. Aparentemente, vive-se o que Slaughter (2005, p. 8, tradução nossa) denomina de "[...] paradoxo da globalização". Na sequência, esclarece ainda que: "Precisamos de mais governo numa escala global e regional, mas não queremos que a centralização do poder de 
decisão e da autoridade coerciva fique tão longe das pessoas realmente governadas. É o paradoxo identificado na União Europeia". (SLAUGHTER, 2005, p. 8, tradução nossa).

Assim, a autora deixa uma pista sobre a ordem ou o status quo desejado pelos Estados hegemônicos. Tal abordagem é compartilhada em certa medida por Huntington (2010, p. 24) quando explica que "[...]. Nesse mundo novo, a política local é a política da etnia e a política mundial é a política das civilizações. [...]".

O outro conceito que deve ser relacionado ao problema proposto, e que demanda maior aprofundamento, é o de soberania. O termo foi cunhado em 1576 por Jean Bodin em Les six livres de la République (BARROS, 2011; BULL, 2002) e, considerando tão somente sua aplicação ao ente Estado, seu sentido clássico vem perdendo as características, pois tem deixado de ser um conceito absoluto (BONAVIDES, 2012) - por mais que pareça um contrassenso.

É bastante razoável admitir que uma das formas mais dissimuladas e efetivas de interferir na soberania de outro Estado, inclusive em tempos de paz, desde o fim da Segunda Guerra Mundial, seja realizada por meio das operações militares de viés especial. Em outras palavras, por meio de atos especializados de guerra, cujas características e formas de emprego constituem o problema principal proposto por este artigo.

Como McManners (2003, p. 8) afirma, as "Forças especiais têm um papel muito maior, muito mais importante a desempenhar nas muitas formas de guerra que enfrentam as Forças Armadas no século XXI [...]" [tradução e grifo nossos]. E é por conta do aumento da importância das operações especiais no universo geopolítico que esta pesquisa se detém na compreensão do emprego das forças especiais em escala mundial.

\section{OPERAÇÕES MILITARES, FORÇAS ESPECIAIS E OPERAÇÕES ESPECIAIS}

Para compreender o conceito de operações especiais, é preciso entender primeiramente o que caracteriza uma operação militar no âmbito das Forças Armadas e o modo como se organizam seus operadores. O Glossário de termos e expressões para uso no Exército explica que operação é uma "Ação militar para a execução de uma missão de natureza estratégica, tática, logística ou de instrução". (BRASIL, 2003, p. 0-3).

Nesse sentido, seriam poucas as atividades militares que não poderiam ser classificadas como operação, tais como as tarefas cotidianas relacionadas à manutenção da vida orgânica das diversas unidades militares. Em outros termos, é admissível afirmar que qualquer tropa está naturalmente apta a realizar operações relacionadas às suas finalidades legais e funcionais, embora se deva ter em consideração que há potencialmente dois tipos de tropas distintas no âmbito das Forças Armadas: as convencionais e as especiais. 
As primeiras, em geral, são compostas de efetivos profissionais - sejam oficiais ou praças, temporários ou de carreira - e efetivos variáveis - formados por soldados que servirão no corpo de tropa por período determinado e dos quais uma pequena parcela poderá constituir o quadro profissional após conclusão de período intensivo de treinamento -, que serão empregados em operações convencionais.

Esses efetivos somados compõem a maior parte da tropa regular, ou seja, dos militares que operam visível (neste caso, pode ser uma operação overt - quando a operação ocorre sem maiores sigilos - ou low visibility - quando há esforço para manutenção da discrição da operação) e invisivelmente (neste caso, pode ser uma operação covert quando a identidade do mandante é dissimulada - ou clandestine - quando a própria operação é dissimulada) em tempo de paz e de guerra em prol da manutenção da defesa do Estado ou de determinado status quo regional internacional (DENÉCÉ, 2009). No Brasil, existe a previsão de uma estrutura semelhante à delineada, denominada Forças Armadas, da qual são selecionados os operadores especiais:

Art. 142. As Forças Armadas, constituídas pela Marinha, pelo Exército e pela Aeronáutica, são instituições nacionais permanentes e regulares, organizadas com base na hierarquia e na disciplina, sob a autoridade suprema do Presidente da República, e destinam-se à defesa da Pátria, à garantia dos poderes constitucionais e, por iniciativa de qualquer destes, da lei e da ordem (BRASIL, 1988, grifo nosso).

Nos termos constitucionais, a missão das Forças Armadas, no Brasil, segue diretrizes institucionais bem definidas que conduzem tanto as tarefas das tropas convencionais quanto das especiais. Sobre as últimas, no entanto, será dedicada maior atenção e em uma escala que ultrapassa os limites do Estado brasileiro.

Mas, antes de avançar, é importante destacar que as normas de acesso e permanência no serviço militar podem variar consideravelmente entre os países ou organizações de natureza diferentes das de um Estado. É o caso da Organização do Tratado do Atlântico Norte (OTAN), por exemplo, cuja estrutura humana é composta exclusivamente por militares do quadro profissional e que também possuem tropas especiais (NORTH ATLANTIC TREATY ORGANIZATION, 2016). Um exemplo de estrutura político-econômica supraestatal que conta com um considerável contingente armado potencial é a União Europeia (UE), pois se trata do somatório de contingentes de militares profissionais das Forças Armadas dos seus Estados-membros.

A partir das informações apresentadas, é possível seguir mais bem fundamentado em direção aos objetivos propostos: o emprego de unidades especializadas em escala mundial. Contudo, deve-se ainda antes compreender que as operações especiais não podem ser 
definidas de modo unívoco, pois possuem acepções diferentes em suas origens (DENÉCÉ, 2009). Nos Estados Unidos (EUA), por exemplo, operações especiais são:

\begin{abstract}
Operações que demandam modos de emprego, técnicas táticas [sic.], equipamento e treinamento únicos, frequentemente conduzidos em ambientes hostis, proibidos ou politicamente sensíveis e caracterizados por uma ou mais das seguintes [condições]: [executada em] momento sensível, [executada em] clandestinidade, [executada em] baixa visibilidade, conduzida com e/ou por meio de forças indígenas, [quando há] exigência de conhecimento regional e/ou que apresente alto grau de risco (SPECIAL OPERATIONS, 2010, p. 221, grifo nosso, tradução nossa).
\end{abstract}

No tocante à expressão operações especiais, o Glossário de termos e expressões para uso no Exército, no Brasil, é omisso. Note-se que houve interesse em destacar o quão especial deve ser a operação para ser caracterizada como tal. Basicamente, é a missão que não pode ser confiada a qualquer militar, mas àquele que seja capaz de atuar em condições mais adversas do que as já esperadas em um teatro de operações convencional. Cabe destaque ainda a algumas condições apresentadas: "momento sensível" e "clandestinidade", o que faz crescer em importância o sigilo das operações em questão, pois poderiam desencadear desentendimentos político-diplomáticos e consequências bélicas de maior envergadura.

O Nato glossary of terms and definitions dá o seguinte significado para operações especiais: "Atividades militares conduzidas por forças especialmente designadas, organizadas, selecionadas, treinadas e equipadas usando técnicas e modos de emprego não convencionais" (SPECIAL OPERATIONS, 2015, p. 2-S-8, grifo nosso, tradução nossa).

É interessante observar que a OTAN, nessa versão do glossário, não se propõe a delinear, mesmo que superficialmente, o perfil das operações especiais às quais se propõe executar, como a doutrina estadunidense faz, mas limita-se a sugerir que as "forças" que a executam lançam mão de "modos de emprego não convencionais".

Ao mesmo tempo em que o glossário omite a definição de forças especiais, é possível deduzir que estão implícitas quando se faz menção a "forças especialmente designadas". É possível verificar em Denécé (2009) que houve considerável supressão de conteúdo na definição de operações especiais no glossário da OTAN.

Uma vez que as operações especializadas não possuem uma doutrina unificada, é de se esperar que as tropas especializadas apresentem características e finalidades consideravelmente distintas entre si - o que dependerá essencialmente da doutrina de emprego dessas unidades pelo seu escalão superior.

Pode-se inferir, portanto, que as tropas especializadas - doravante forças especiais possuem características tão distintas das convencionais quanto diversas em relação às suas atribuições. Em todo caso, sabe-se que para atingir alto nível de sucesso nas operações 
diferenciadas que Ihes são atribuídas, as operações especiais exigem pessoal, materiais, técnicas e estratégias diferenciadas (CLANCY, 2001; DENÉCÉ, 2009; FRANCE, 2016).

$\mathrm{Na}$ sequência, serão apresentadas algumas definições para forças especiais que essencialmente provêm dos EUA, país de origem do conteúdo doutrinário já aperfeiçoado de tropas especializadas durante e após a Segunda Guerra Mundial (DENÉCÉ, 2009; PINHEIRO, 2008; SWANSTON, 2014), mas que já havia sido testado em combate pela GrãBretanha em meados de 1940 (YOUNG, 1975) - trata-se da popularização e aperfeiçoamento do conceito de operador comando (DUNNIGAN, 2008; PINHEIRO, 2008) nos planejamentos estratégicos de Estado-Maior dos mais diversos países. Conforme consta no Dicionário etimológico Nova Fronteira da Língua Portuguesa, o termo comando possui a seguinte definição:

|| comando | -mman- 1813 | Do fr. commande. É interessante assinalar que o port. comando passou ao africâner (língua holandesa falada na República Sul-Africana) commando (kommando), na acepção específica de 'unidade tática do exército dos bôeres, constituída de grupos de choque treinados para missões especiais'; daí o voc. passou ao ing. commando e, por intermédio deste, às demais línguas da Europa, onde foi muito empregado durante a $2^{\mathrm{a}}$ guerra mundial (COMANDO, 2001, p. 197, grifo do autor).

No estadunidense Department of Defense Dictionary of Military and Associated Terms consta a seguinte definição para forças especiais, com diferença praticamente imperceptível quando confrontada com o termo supracitado: "Forças do exército dos Estados Unidos organizadas, treinadas e equipadas para conduzir operações especiais com ênfase à aptidão em guerras não convencionais. Também chamadas FE [SF]" (SPECIAL FORCES, 2010, p. 221, tradução nossa).

No Brasil, o Glossário de termos e expressões para uso no Exército apresenta sentido análogo no tocante à expressão forças especiais: "Elementos de emprego estratégico, destinados a conduzir a guerra de guerrilha, outras operações irregulares, bem como atividades correlatas, tendo em vista facilitar o cumprimento da missão de uma força militar" (BRASIL, 2003, p. F-11).

Para que tais elementos possuam alguma desenvoltura tática, no Brasil sua organização mínima é a de um destacamento de forças especiais, que seria o "Elemento básico do emprego de forças especiais, composto de pessoal altamente especializado nas várias atividades necessárias à condução de guerra irregular" (BRASIL, 2003, p. D-9).

Uma vez compreendidas as principais definições de forças especiais e as operações que a caracterizam, cresce em importância o entendimento acerca da essência que as compõem. Segundo Denécé (2009, p. 123), há algumas características que definem tais atividades militares: 
Do ponto de vista histórico, as operações especiais caracterizam-se por seis critérios significativos, que muito claramente as diferenciam das ações comando: a busca de um efetivo decisivo, que se pode qualificar de 'efeito de ruptura'; o caráter altamente perigoso das missões; o volume reduzido do efetivo engajado; seu modo de ação não convencional; o domínio da violência; a confidencialidade em relação às unidades e a seu pessoal [grifos nossos].

Note-se que Eric Denécé, ao qualificar as operações especiais, as diferencia das ações executadas pelos comandos, conforme já apontado. A maior ou menor dificuldade em discernir um modelo de operação do outro se deve à própria concepção da natureza das operações especiais de cada governo ou organismo em questão. Quanto aos objetivos das operações especiais, Denécé (2009, p. 238) explica como se constituem nos EUA:

As missões confiadas às forças especiais norte-americanas são claramente definidas pelo Pentágono: reconhecimento especial; ação direta (tomada de objetivos na retaguarda do inimigo, inclusões, demolições); diversionismo tático; resgate em combate; guerra não convencional (guerrilha, contraguerrilha, recrutamento de combatentes nativos); antiterrorismo e contraterrorismo; retirada de cidadãos, operações humanitárias e de desenvolvimento interno dos países. Operações psicológicas e guerra da informação (Infowar); de contraproliferação; de instrução e de treinamento de forças estrangeiras.

Em seguida, Denécé (2009, p. 238-239) demonstra que há diferenças operacionais quanto ao emprego das forças especiais no Reino Unido em relação aos Estados Unidos:

No Reino Unido, cinco regras definem as condições do emprego das forças especiais britânicas: apenas objetivos de alto valor estratégico devem ser designados para elas; a ação deve ser comandada no mais alto nível; as unidades devem ter acesso a todas as informações disponíveis, mesmo as mais secretas; diretrizes de ação claras devem ser estabelecidas; a operação deve ser realizada no mais absoluto sigilo. As forças especiais britânicas congregam um número reduzido de pessoal altamente qualificado, cuja formação é longa e cara. Por isso [sic.] a relação custo/eficácia faz com que as forças especiais só sejam utilizadas contra objetivos de alto valor agregado para o comando. Nesse contexto, aos destacamentos de forças especiais cumpre realizar missões de reconhecimento estratégico (localização de postos de comando adversários, por exemplo), ações ofensivas (destruição de equipamentos viários, vias férreas, infraestruturas aeroportuárias e portuária, centrais de produção de energia [etc.]), de guerra não convencional (guerrilha, contraguerrilha, recrutamento de combatentes nativos) e ações diversionistas.

Cabe apontar que o modelo de emprego operacional britânico influenciou indelevelmente o modus operandi das forças especiais israelenses a Sayeret Matkal, "unidade de reconhecimento" da Israel Defense Forces (LEWIS, 2015), no que se refere ao combate ao terrorismo transnacional perpetrado por grupos terroristas muçulmanos como 0 
libanês xiita Hezbollah e o palestino sunita Hamas. Por fim, Denécé (2009, p. 239-240) também deixa claras as atribuições das forças especiais na França:

[...] as atribuições do Commandement des Opérations Spéciales (COS) compreendem o planejamento, a coordenação e a condução das ações 'realizadas por unidades das forças armadas especialmente organizada, treinadas e equipadas para a consecução de objetivos militares ou paramilitares'. O COS é empregado em operações não convencionais, inclusive na obtenção de informações necessárias à ação. As missões do COS, autônomas ou em apoio a forças convencionais, são realizadas no âmbito de dois domínios: a ação direta e as ações de ambiente. As ações diretas compreendem: o apoio operacional a unidades em campo por meio de técnicas específicas, o reconhecimento na retaguarda do inimigo; a neutralização, relacionada a competências próprias dos comandos e que relaciona-se em particular com o contraterrorismo; a libertação de reféns, a realização de ações retaguarda do inimigo, aprisionamento de indivíduos determinados e operações diversionistas no campo inimigo; a segurança das comunidades francesas e retirada de cidadãos. As ações ditas de ambiente compreendem: a assistência militar no estrangeiro; a proteção das autoridades militares nacionais; e os assuntos civis-militares (ACM), como a realização de perícias iniciais no teatro de operações visando avaliar de maneira precisa a área em crise (contexto político, econômico, humano), em proveito da ação de tropas convencionais. O COS participa também das operações psicológicas [...].

No âmbito da UE, a viabilidade da criação de forças especiais já se encontrava em fase de estudo em 2004 (MODIGS, 2004). Em 2013, a UE publica informativo ostensivo que prevê a utilização de tropas especializadas em seu organograma operacional (EUROPE UNION, 2013).

\section{ORGANIZAÇÃO DAS FORÇAS ESPECIAIS E BREVE COMPARATIVO DE CENÁRIOS DE EMPREGO}

Partindo da premissa já apresentada, na qual a diversidade doutrinária do emprego das forças especiais ao redor do mundo é notadamente multiforme, depreende-se que a disposição e a dinâmica das suas estruturas organizacionais sejam consideravelmente singulares, mesmo se comparadas entre si. Para demonstrar isso, este tópico deter-se-á sobre a organização dessas forças com vistas a demonstrar diferenças e semelhanças entre as forças especiais brasileiras e as estadunidenses.

O General Álvaro de Souza Pinheiro (2008), na apresentação de Ações de comandos: operações especiais, comandos e o futuro da guerra dos EUA, descreve de modo detalhado como se deu a formação dos quadros voltados às operações especiais no âmbito das Forças Armadas brasileiras e como esses elementos estratégicos são empregados nos mais diversos tipos de operações, tanto no Brasil quanto no exterior. 
Cabe ressaltar que somente a apresentação da versão em português é originalmente brasileira. Trata-se de uma das escassas referências de qualidade, em Língua Portuguesa, acessíveis ao público civil e que compõe a única obra, já esgotada, da Biblioteca do Exército dedicada ao tema operações especiais. A obra original, The perfect soldier: special operations, commandos and the future of US warfare, de 2003, é creditada ao analista militar estadunidense James F. Dunnigan. O Brasil conta com uma Brigada de Operações Especiais, presente na estrutura orgânica do Exército Brasileiro, que apresenta as seguintes unidades:
a) Comando e Estado-Maior;
b) Centro de Instruções de Operações Especiais;
c) $1^{\circ}$ Batalhão de Forças Especiais;
d) $1^{\circ}$ Batalhão de Ações de Comandos;
e) $3^{\text {a }}$ Companhia de Forças Especiais;
f) Destacamento de Operações Psicológicas;
g) Destacamento de Apoio às Operações Especiais;
h) $1^{\circ}$ Pelotão de Defesa Química, Biológica e Nuclear;
i) $6^{\circ}$ Pelotão de Polícia do Exército; e
j) Base Administrativa da Brigada de Operações Especiais. (PINHEIRO, 2008).

Operacionalmente, no Brasil, o comando é uma espécie de operador especial. Na concepção militar estadunidense, diferencia-se mais facilmente o militar ranger, operador especial análogo aos comandos britânicos, mas que apresenta consideráveis diferenças de emprego tático daqueles, do militar special force. (PINHEIRO, 2008).

A Brigada está localizada praticamente em sua totalidade em Goiânia (GO), com exceção ao Centro de Instruções de Operações Especiais, em Niterói (RJ), e a $3^{a}$ Companhia de Forças Especiais, em Manaus (AM).

Todas as unidades relacionadas estão subordinadas ao Comando Militar do Planalto e vinculado ao Comando de Operações Terrestres - ambos sediados em Brasília - sendo este último para efeito de emprego e preparo (PINHEIRO, 2008). Outro aspecto a ser destacado é a existência de um Destacamento Contraterrorismo, vinculado ao $1^{\circ}$ Batalhão de Forças Especiais - postura doutrinária que coaduna claramente com a estadunidense. Além das unidades mencionadas, o Exército Brasileiro conta com tropas especializadas com vistas à atuação em cenários operacionais diversos, a saber:

a) Guerreiros de Selva, concluintes do curso de operações na selva, desenvolvido no Centro de Instrução de Guerra na Selva, em Manaus (AM) - atuam nos mais diversos cenários amazônicos, de importância estratégica ímpar para as Forças Armadas do Brasil; 
b) Combatentes de Caatinga, concluintes do estágio de operações na caatinga, desenvolvido no $72^{\circ}$ Batalhão de Infantaria Motorizado, em Petrolina (PE) - atuam em ambiente semiárido;

c) Combatentes do Pantanal, concluintes do estágio de operações no Pantanal, desenvolvido no $17^{\circ}$ Batalhão de Fronteira, em Corumbá (MS) - atuam em ambiente pantaneiro; e

d) Paraquedistas, concluintes dos diversos cursos realizados pela Brigada Paraquedista, localizada no Rio de Janeiro (RJ). (PINHEIRO, 2008).

Cabe destacar que os militares destacados em tais unidades, apesar de suas características operacionais diferenciadas, não estão enquadrados na estrutura da Brigada de Operações Especiais. Ainda há outras unidades especializadas, mas que também não caracterizariam unidades especiais, no sentido estrito, ou seja, voltadas para operações especiais - mas serviriam de apoio àquelas.

Seria o caso das unidades militares de selva, aeromóveis (aerotransportadas), de montanha, cavalaria mecanizada e motorizada, além de unidades como o Centro de Instrução de Operações de Garantia da Lei e da Ordem, sediado em Campinas, por exemplo.

A Marinha do Brasil também possui operadores especiais: os mergulhadores de combate - do Grupo de Mergulhadores de Combate - e os fuzileiros navais - do Batalhão de Operações Especiais de Fuzileiros Navais. Enquanto os primeiros atuam em ambiente aquático, os últimos agem em ambiente terrestre - comandos anfíbios (PINHEIRO, 2008).

Assim como a Marinha Brasileira e o Exército Brasileiro, a Força Aérea Brasileira possui unidades especiais: o Esquadrão Aeroterrestre de Salvamento e os Pelotões de Operações Especiais dos Batalhões de Infantaria, inclusive com o emprego de paraquedistas em missões do tipo SAR (Search and Rescue), ou seja, operações de busca e salvamento. Pinheiro chama atenção para a interoperabilidade dessas forças quando explica que:

Muito embora as Operações Especiais possam ser executadas por elementos especializados de uma única Força Singular (e essa era a rotina observada no século passado), as mais recentes e bem-sucedidas experiências demonstram que a probabilidade de êxito é intensivamente incrementada quando conduzidas como operações combinadas. Considerando a relevância que as FOpEsp [Forças de Operações Especiais] ganharam em função das crescentes demandas de Guerra Irregular, característica dos Conflitos de $4^{a}$ Geração do século XXI e, principalmente, buscando maximizar o esforço na prevenção e no combate ao terrorismo transnacional [...] foram criados Comandos Combinados de Operações Especiais, estabelecidos no mais alto nível de comando e controle de Forças Armadas como as dos EUA, Reino Unido, Rússia, China, França, Israel, Austrália e Nova Zelândia, entre outros. Todos com a responsabilidade de orientar, coordenar e controlar o adestramento, o 
planejamento e o emprego combinado dos meios terrestres, navais e aéreos das FOpEsp.[...] no Brasil, a interoperabilidade tem-se manifestado por meio da constituição de Forças Tarefa Combinadas de Operações Especiais [...] (PINHEIRO, 2008, p. 48).

Pinheiro (2008) destaca a "Operação ASPA" como oportunidade em que se pôde empregar forças especiais no Brasil na condução de medidas contraterrorismo. A operação ocorreu em Brasília (DF), em maio de 2005, durante a Conferência de Cúpula América do Sul - Países Árabes (ASPA).

Outra operação especial de âmbito internacional (Brasil-Colômbia) em que houve operação das forças especiais brasileiras foi a "Operação Traíra". Pinheiro (2005) detalha que às:

12:00 horas de uma terça-feira, dia 26 de fevereiro de 1991. Cerca de 40 elementos que se declararam guerrilheiros das Forças Armadas Revolucionárias Comunistas (FARC) - Comando Simón Bolívar - Facção Força e Paz, realizam uma incursão em território nacional e atacam um Destacamento do Exército Brasileiro estacionado em instalações semipermanentes [sic.], às margens do rio Traíra, fronteira entre o Brasil e a Colômbia. $O$ ataque foi efetuado por três escalões, dos quais um, o de apoio de fogo, permaneceu na margem colombiana, enquanto os outros dois, de assalto e de segurança, investiram o acampamento. Inicialmente, com preciso fogo de atiradores de escol, foram eliminados os sentinelas [sic.] da hora, e a seguir, desencadeado intenso fogo de armas automáticas contra as instalações do Destacamento, cujos integrantes, surpreendidos, tentaram, sem sucesso, reagir. Em decorrência da ação, da guarnição de 17 homens, resultaram três soldados mortos e nove feridos. Morreram também dois garimpeiros clandestinos colombianos que estavam detidos no posto aguardando evacuação para Vila Bittencourt/AM. Na finalização da operação, os guerrilheiros colombianos apropriaram-se de estações rádio, munição, uniformes e todo o armamento do posto, conduzindo todo o material para o seu território. Aparentemente, não sofreram baixas. Portavam armamento automático HK $5.56 \mathrm{~mm}$ e armas de caça calibre 12 . Trajavam uniformes de cor verde claro [sic.] e botas de borracha do tipo "sete léguas". Faziam parte do comando atacante duas mulheres identificadas como já tendo sido anteriormente presas no Destacamento.

O General Pinheiro continua seu relato e destaca que:

A ação de 26 Fev 91 das FARC no rio Traíra desencadeou o planejamento e a execução de uma operação conjunta efetuada pelas Forças Armadas Brasileiras e Colombianas, denominada "Operação Traíra". Esta Operação foi a principal conseqüência [sic.] da Reunião Extraordinária Regional Bilateral Brasil/Colômbia, com a participação, pelas forças colombianas, de autoridades do Comando da IV División del Ejército Nacional de Colombia, sediado em Vila Vicenzio/Col e, pelas forças brasileiras, de autoridades do Comando Militar da Amazônia, sediado em Manaus/AM. [...] Mais uma vez foi ratificado que a presença dos especialistas em guerra irregular e combate não-convencional [sic.] do $1^{\circ}$ Batalhão de Forças Especiais $\left(1^{\circ}\right.$ BFEsp), sediado no Rio de Janeiro, através da ação de um Destacamento de Ação Imediata, integrado por frações de Forças Especiais e Ações de Comandos, se faz imprescindível ao comando da operação, em situações dessa natureza. (PINHEIRO, 2005, grifo nosso). 
Operações conjuntas, em viés mais amplo, é uma temática abordada por Florin Negulescu (2011) no seu artigo Strategic combined Joint Special Operations and the balance between national and common interest. Também é interessante notar que as tropas compostas pelos rangers estão subordinadas a uma estrutura governamental denominada US Joint Special Operations Command (JSOC), ou "Comando de Operações Especiais Conjuntas dos Estados Unidos" (MCMANNERS, 2003, tradução nossa). Além da "Operação Traíra", houve a "Operação Perro Loco", que, de acordo com Pinheiro:

\begin{abstract}
Em novembro de 1991, outra operação de monta foi desencadeada pelo CMA para fazer face às latentes ameaças provodadas [sic.] pela ação das FARC, na fronteira com a Colômbia. Esta operação denominada "Operação Perro Loco' foi realizada na região de lauaretê/AM e Querarí/AM, conhecida como "Cabeça do Cachorro". Empregou efetivos do $5^{\circ}$ BIS $\left[5^{\circ}\right.$ Batalhão de Infantaria de Selva], sediado em São Gabriel da Cachoeira/AM, do $1^{\circ}$ BFEsp, e uma Força de Helicópteros com 14 aeronaves da Bda Av Ex [Brigada de Aviação do Exército]. A exemplo da "Operação Traíra", a "Operação Perro Loco" se constituiu numa magnífica demonstração de operacionalidade dos elementos envolvidos, atingindo de forma plena o seu grande objetivo que era dissuadir, de forma definitiva, a execução de incursões por parte da narcoguerrilha colombiana naquela região (PINHEIRO, 2005, grifo nosso).
\end{abstract}

De modo análogo ao Brasil, os Estados Unidos possuem unidades do tipo comandos e do tipo forças especiais, com atribuições distintas das tropas convencionais e entre si. Sobre essas unidades de forças especiais, Pinheiro (2008, p 306-307) explica que:

[...] são a maior unidade militar de alta prontidão emergencial (a menor é a Força Delta), pronta para lançar-se, em uma dificuldade imediata, ao alémmar, em menos de 24 horas. Um dos três batalhões dos rangers está sempre designado para esse dever, levando um mês na ativa (pronto para partir 18 horas após ser notificado) e dois meses fora dessa escala, totalmente voltado para o treinamento [...] $\bigcirc$ Quartel-General do $75^{\circ}$ Regimento Rangers localiza-se na Geórgia, Fort Benning. O primeiro batalhão do $75^{\circ}$ Regimento (1/75) está estabelecido no Campo de Aviação do Exército Hunter, Geórgia; o $2^{\circ}[. .$.$] , no Fort Lewis, em Washington; o 3^{\circ}$ [...] no Fort Benning [...]

A Força Delta seria uma unidade operacional secreta também é destino possível de operadores rangers e special forces e é voltada para operações contraterrorismo. É subordinado, em companhia dos SEALs (US Navy), ao JSOC - (PINHEIRO, 2008). Para melhor compreensão do funcionamento em emprego da Força Delta, recomenda-se a leitura de Força Delta: a história da unidade de elite antiterrorismo norte-americana (HANEY, 2003), que inspirou a série fictícia The Unit (CBS) e foi ao ar a partir dos Estados Unidos entre 2006 e 2009, em canal pago (CBS/FOX), posteriormente em canal aberto no Brasil (Band), e também é comercializada em DVDs. 
Além dessas unidades de pronto-emprego, há a Brigada de Treinamento Rangers, composta por três Batalhões (PINHEIRO, 2008). O General Pinheiro (2008) continua explicando que, desde 1990, os EUA utilizam a seguinte distribuição organizacional para as forças especiais, com suas respectivas orientações regionais:

a) $1^{\circ}$ Grupo de Forças Especiais - Leste da Ásia;

b) $3^{\circ}$ Grupo de Forças Especiais - Caribe e oeste da África;

c) $5^{\circ}$ Grupo de Forças Especiais - Oriente Médio e sul da Ásia;

d) $7^{\circ}$ Grupo de Forças Especiais - América Latina;

e) $10^{\circ}$ Grupo de Forças Especiais - Europa;

f) $19^{\circ}$ Grupo de Forças Especiais - Unidade de reserva do $1^{\circ}$ e $5^{\circ}$ Grupos;

g) $20^{\circ}$ Grupo de Forças Especiais - Unidade de reserva do $7^{\circ} \mathrm{Grupo}$.

Cada Grupo, conforme Pinheiro (2008, p. 311), “[...] tem uma pequena unidade de quartel-general e três batalhões de Forças Especiais. [...] O número total de soldados do grupo das Forças Especiais é de, aproximadamente, 120 tropas".

Em termos comparativos, portanto, é possível verificar o quanto avançou a doutrina e o quão grande é a capacidade de emprego de forças especiais pelos EUA. Contudo, é uma comparação que deve ser pautada pela razoabilidade, considerados os investimentos do Produto Interno Bruto (PIB) dos dois países (CENTRAL INTELLIGENCE AGENCY, 2016a 2016b), assim como própria dimensão das respectivas Forças Armadas.

\section{CONSIDERAÇÕES FINAIS}

É possível que o fato mais notável na obtenção de referencial teórico de qualidade voltado para o tema deste artigo ainda é a escassez de fontes bibliográficas em Língua Portuguesa, mesmo sabendo que a Língua Inglesa é o Esperanto da ciência contemporânea - como não poderia ser diferente, pois, foi nesse idioma que a maior parte das consultas às fontes bibliográficas se deteve.

No tocante à apreensão do fenômeno forças especiais, compreende-se que ao mesmo tempo em que se trata de um fenômeno militar, trata-se de um fenômeno político, que consiste na tentativa de imposição de uma vontade de Estado - ou de estrutura política que tenha força equivalente -, seja em um teatro de operações ostensivo ou dissimulado.

Atentando ainda que, para a construção de uma ideia mais elaborada em torno da dissimulação das operações especiais cobertas e clandestinas, seria necessário acesso a registros de natureza classificada e a operadores especiais dispostos a fornecer informações secretas, condições que tornariam praticamente inviável uma pesquisa desse tipo. 
Contudo, para maior aprofundamento da leitura sobre operações especiais cobertas e clandestinas executadas além das fronteiras estatais, recomenda-se a leitura de Mossad: os carrascos do Kidon: a história do temível grupo de operações especiais de Israel, de Eric Frattini (2014). Outra sugestão acerca de operações dessa natureza executadas pelo Estado de Israel, embora se trate de obra de ficção, é a série Fauda (Yes Oh), lançada originalmente na TV israelense (2015), e disponibilizada na Netflix, desde 2016.

Enfatiza-se que a existência do fenômeno em questão não é mera casualidade, pois a doutrina moderna de emprego de forças especiais tem genealogia anglo-saxônica, visto que a maior parte da doutrina difundida foi apropriada e aperfeiçoada inicialmente pelos países anglófonos - com destaque para a Grã-Bretanha e os EUA - após a Segunda Guerra Mundial.

Trata-se, evidentemente, de um tema que apresenta certa complexidade, pois trata de organismos e de ações políticas de Estado-Maior que nem sempre chegam ao conhecimento das mídias de massa, ou mesmo às discussões de teor acadêmico, o que o torna ainda um tanto mais difícil para abordar e analisar.

Por fim, pretende-se que esta produção contribua para melhor compreensão da influência do fenômeno forças especiais na composição das relações políticas internacionais contemporâneas. Em outras palavras, espera-se que a abordagem propedêutica proposta pelo texto possa estimular o interesse por esse subcampo tão peculiar do estudo das operações militares em escala mundial.

\section{REFERÊNCIAS}

AGNEW, J. Globalization \& sovereignty. Maryland: Rowman \& Littlefield, 2009.

.; CORBRIDGE, S. Mastering space: hegemony, territory and international political economy. London: Routledge, 1995.

BARROS, A. R. G. de. 10 Lições sobre Bodin. Petrópolis: Vozes, 2011.

BONAVIDES, P. Ciência política. São Paulo: Malheiros, 2012.

BRASIL. Constituição (1988). Constituição da República Federativa do Brasil de 1988.

Diário Oficial da União, Brasília, 05 out. 1988. 191-A, p. 1. Brasília, 2003.

Ministério do Exército. Glossário de termos e expressões para uso no Exército.

BULL, H. A sociedade anárquica: um estudo da ordem na política mundial. São Paulo: Imprensa Oficial de São Paulo; Brasília: Universidade de Brasília, Instituto de Pesquisa de Relações Internacionais, 2002. 
CENTRAL INTELLIGENCE AGENCY - CIA. Library. The World Factbook. North America: United States. Disponível em: <https://www.cia.gov/library/publications/the-worldfactbook/geos/us.html>. Acesso em: $6 \mathrm{dez}$. 2016a.

South America: Brazil. Disponível em: <https://www.cia.gov/library/publications/theworld-factbook/geos/br.html>. Acesso em: 6 dez. 2016b.

CLANCY, T. Special forces: a guided tour of U.S. Army Special Forces. New York: Berkley Publishing Group, 2001.

CLAUSEWITZ, C. von. Da guerra. São Paulo: M. Fontes, 2010.

COMANDO. In: CUNHA, A. G. Dicionário etimológico nova fronteira da Língua portuguesa. Rio de Janeiro: Nova Fronteira, 2001. p. 197.

CORREIA, P. de P. Manual de geopolítica e geoestratégia: conceitos, teorias e doutrinas. Coimbra: Almedina, 2010. v. 1.

DENÉCÉ, E. A história secreta das forças especiais: de 1939 a nossos dias. São Paulo: Larousse do Brasil, 2009.

DODDS, K. Geopolitics: a very short introduction. Oxford: Oxford University Press, 2014.

DUNNIGAN, J. F. Ações de comandos: operações especiais, comandos e o futuro da guerra dos EUA. Rio de Janeiro: Biblioteca do Exército, 2008.

DUROSELLE, J.-B. Todo império perecerá. Brasília: Universidade de Brasília; São Paulo: Imprensa Oficial de São Paulo, 2000.

EUROPE UNION. Common Security and Defence Policy. EU Battlegroups. 2013.

Disponível em:

<https://www.consilium.europa.eu/uedocs/cms data/docs/pressdata/en/esdp/91624.pdf>.

Acesso em: 17 set. 2016.

FRANCE. Ministère des Armées. Department of Defense. Equipements. Disponível em: $<$ http://www.defense.gouv.fr/terre/equipements/materiels-forces-speciales $>$. Acesso em: 17 set. 2016.

GOTTMANN, J. The basic problem of political geography: the organization of space and the search for stability. Tijdschrift voor Economische en Sociale Geografie, Amsterdam, v. 73, n. 6, p. 340-349, 1982.

HANEY, E. L. Inside delta force: the story of America's elite counterterrorist unit. New York: Random House Publishing, 2003.

HUNTINGTON, S. P. O choque de civilizações e a recomposição da ordem mundial. Rio de Janeiro: Objetiva, 2010.

MCMANNERS, $\mathrm{H}$. Ultimate special forces: the insider's guide to the world's most deadly commandos. New York: Ed. DK, 2003.

MODIGS, R. Special forces capabilities of the European Union Military Forces Fort Leavenworth: School of Advanced Military Studies-SMAS, 2004. 
MORGENTHAU, H. J. Política entre las naciones: la lucha por el poder y la paz. Buenos Aires: GEL, 1986.

NEGULESCU, F. Strategic combined Joint Special Operations and the balance between national and common interest. Journal of Defense Resources Management, Brasov, v. 2, n. 1, p. 39-46, 2011.

NORTH ATLANTIC TREATY ORGANIZATION. Special Operation Forces. Disponível em: <http://www.nato.int/cps/en/natohq/topics_105950.htm>. Acesso em: 16 set. 2016.

PINHEIRO, A. de S. Apresentação. In: DUNNIGAN, J. F. Ações de comandos: operações especiais, comandos e o futuro da guerra dos EUA. Rio de Janeiro: Biblioteca do Exército, 2008. p. 7-53.

Guerrilha na Amazônia: uma experiência no passado, o presente e o futuro. 2005. Disponível em: <http://www.defesanet.com.br/toa/noticia/5195/TOA-GUERRILHA-NAAMAZONIA--A-Experiencia-do-Rio-Traira----Parte-3>. Acesso em: 27 nov. 2016.

SLAUGHTER, A. M. A new world order. New Jersey: Princeton University, 2005.

SPECIAL FORCES. In: UNITED STATES. Department of Defense. Dictionary of military and associated terms: joint publication 1-02: amended through 15 February 2016. Washington: Pentagon, 2010, p. 221.

SPECIAL OPERATIONS. In: NORTH ATLANTIC TREATY ORGANIZATION. NATO glossary of terms and definitions (English and French): AAP-06. Brussels, 2015. p. 2-S-8.

In: UNITED STATES. Department of Defense. Dictionary of military and associated terms: joint publication 1-02: amended through 15 February 2016. Washington: Pentagon, 2010. p. 221.

SWANSTON, A. The atlas of special operations of World War II. New York: Skyhorse Publishing, 2014.

WALTZ, K. N. O homem, o estado e a guerra: uma análise teórica. São Paulo: M. Fontes, 2004.

YOUNG, P. Comandos: os soldados fantasmas. Rio de Janeiro: Renes, 1975.

Recebido: fevereiro de 2018. Aceito: junho de 2018. 